https://www.journal-imab-bg.org

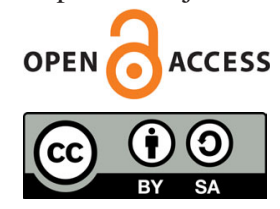

Case report

\title{
BILATERAL TORTUOUS INTERNAL CAROTID ARTERIES - a case report, otorhinolaryngologic and general clinical implications.
}

\author{
Klaudia Ziolkowska ${ }^{1}$, Chavdar Bachvarov ${ }^{2}$, Nicolay Sapundzhiev ${ }^{3}$, Petia \\ Genova ${ }^{3}$. \\ 1) Collegium Medicum in Bydgoszcz, Faculty of Medicine, Nicolaus Copernicus \\ University in Torun, Poland \\ 2) Department of Radiology, Saint Marina Varna Hospital, Bulgaria \\ 3) Department of ENT, Medical University in Varna, Saint Marina Varna Hospital, \\ Bulgaria.
}

\begin{abstract}
Variations in the anatomical course of the cervical portion of the internal carotid arteries appear to be more common than expected and recognised, reaching a prevalence of $10-43 \%$. A case of atypical course of both internal carotid arteries with medial transposition is described. The general clinical implications are presented in the base of review the literature.

In an otherwise healthy adult female pulsating masses on the posterior oropharyngeal wall were observed on transnasal endoscopy for other indications. Contrast enhanced computer tomography revealed bilateral symmetrical tortuous internal carotids, angulated medially at the level of $\mathrm{C} 2$ and almost contacting in the midline. However, no significant stenosis was ascertained within any of the evaluated arteries. The patient was informed about potential risk during the prospective surgical procedures around the pharyngeal area. Carotid tortuosity may present a potential threat in otolaryngological surgery. Whereas no symptoms occur in the most of the patients and the condition can be an accidental finding during physical examination as well as endoscopic or radiological evaluation, the frequency in the general population is higher than assumed. The treatment is not indispensable, however, setting down in the patient's medical history is important. Medical specialists should keep in mind that aberrant internal carotid arteries pose a risk of severe haemorrhage when even routine surgical or diagnostic procedures within the head and neck region are performed.
\end{abstract}

Keywords: internal carotid arteries, tortuosity, oropharynx, retropharyngeal pulsation

\section{INTRODUCTION}

An aberrant course of the internal carotid arteries (ICA) is caused either by their congenital disturbances (in children) or acquired changes including hypertension and alteration within the vascular wall (in adults). In the general population, the frequency of carotid tortuosity is about $10-43 \%$ of the patients $[1,2,3]$. The discrepancies result from the fact that many cases are asymptomatic and nonidentified. Anatomical variations of the ICAs can be related to the development such as aplasia or hypoplasia and also to their inappropriate course (tortuosity, kinking, coiling) $[4,5]$. There is certain evidence for the higher incidence in females and in elderly [2, 3]. Even though this abnormality is usually found accidentally without any significant clinical signs, there is a possibility that some symptoms can occur e.g. dysphagia, dysphonia, snoring, foreign body sensation in the throat, difficulties in breathing. The term "dangerous loop" is used when this anomaly poses a risk for the surgical procedures performed within the area of the neck [6, 7, 8, 9]. It is compelling for otolaryngologists, radiologists, surgeons, anaesthesiologists and other specialists to keep in mind that this kind of distinctness can be encountered, to distinguish it from other pathologies like aneurysms, neoplasms or abscesses. Although the treatment of ICAs' tortuosity diagnosed in adulthood is usually dispensable, the symptomatic patients with higher risk of the life-threatening complications may require more thorough clinical observation and even surgical management.

The diagnosis and assessment of the atypical vessels are based on CECT (contrast-enhanced Computer Tomography) and contrast MRI (Magnetic Resonance Imaging) as well as classical angiography. The Doppler ultrasound is a useful and non-invasive technique but could make the evaluation more difficult and inadequate $[2,7$, $10]$.

This article presents the case of an asymptomatic patient with a bilateral atypical course of ICAs, which has been found incidentally during a physical examination.

\section{CASE REPORT}

A 63-year-old woman presented to ENT clinic with a sinus headache, fever, dysphonia and episodes of dyspnoea which had occurred a few days before admission. During the physical examination, the symptoms of a viral infection of the upper airways were recognised. The patient was otherwise healthy, without any particular risk factors. She was not on any regular medication. Apart from an allergy on quinidine, she did not have a history of any chronic disorders, and her family history was negative as well. 
The anterior rhinoscopy showed slightly deviated nasal septum and a bilateral purulent secretion within the nasal cavity. In the pharyngoscopic assessment, the signs of mild chronic pharyngitis and postnasal drip could be seen. Rhinopharyngolaryngoscopy was done using a flexible endoscope. On the posterior wall of the epipharynx, symmetrical bilateral bulging and pulsating masses were observed under otherwise normal epithelium (Fig. 1). Upon examination, the larynx showed normal mobility. Contrastenhanced CT was performed. The picture presented an atypical tortuous course of both internal carotid arteries, which were medially angulated at the level of C2 (Fig.24). However, no significant stenosis was ascertained within any of the evaluated arteries. The patient was informed about potential risk during the prospective surgical procedures around the pharyngeal area. Sinusitis was managed by antibiotic therapy and nasal decongestants. She was discharged to home with a good general condition.

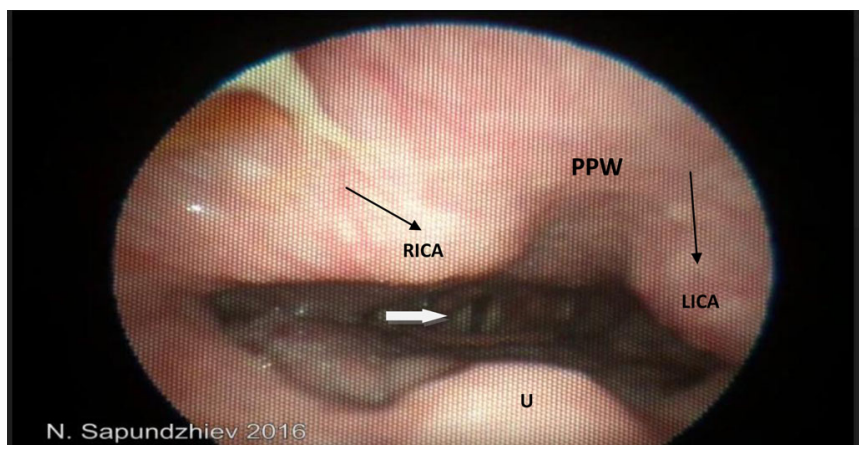

Fig. 1. An endoscopic video demonstrating bilateral pulsating retropharyngeal masses (black arrows). Deeper the vocal cords are visualised (white arrow). $P \boldsymbol{P W}-$ posterior pharyngeal wall, RICA - the right internal carotid artery, LICA - the left internal carotid artery, $\boldsymbol{U}$ - the uvula.

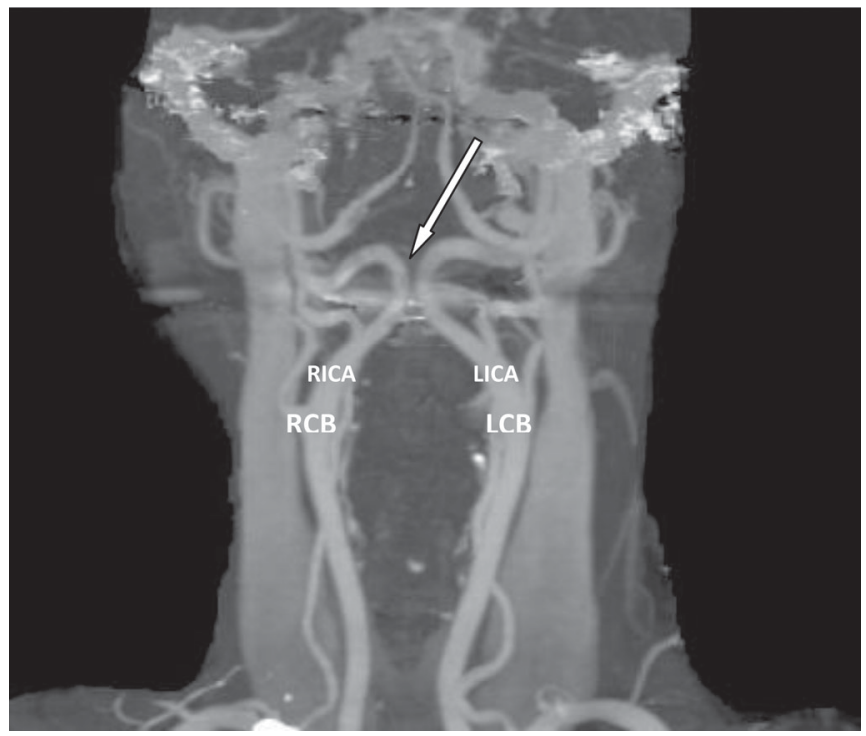

Fig. 2. Tortuous ICA presented in the CT angiogram. Coronal CTA shows the medial deviation of the both ICA at the level of the oropharynx. Above the carotid bulb (bifurcation of the common carotid artery) the right and left
ICA form the loops orientated towards the midline which afterwards turns back to the normal lateral position (arrow). Coronal images allow noticing easily the arcuated, medially deviated segments of the kinked and compensatory elongated vessels.

$\boldsymbol{R I C A}$ - the right internal carotid artery, $\mathbf{L I C A}$ - the left internal carotid artery, $\boldsymbol{R} \boldsymbol{C B}$ - the right carotid bulb, $\mathbf{L C B}$ - the left carotid bulb.
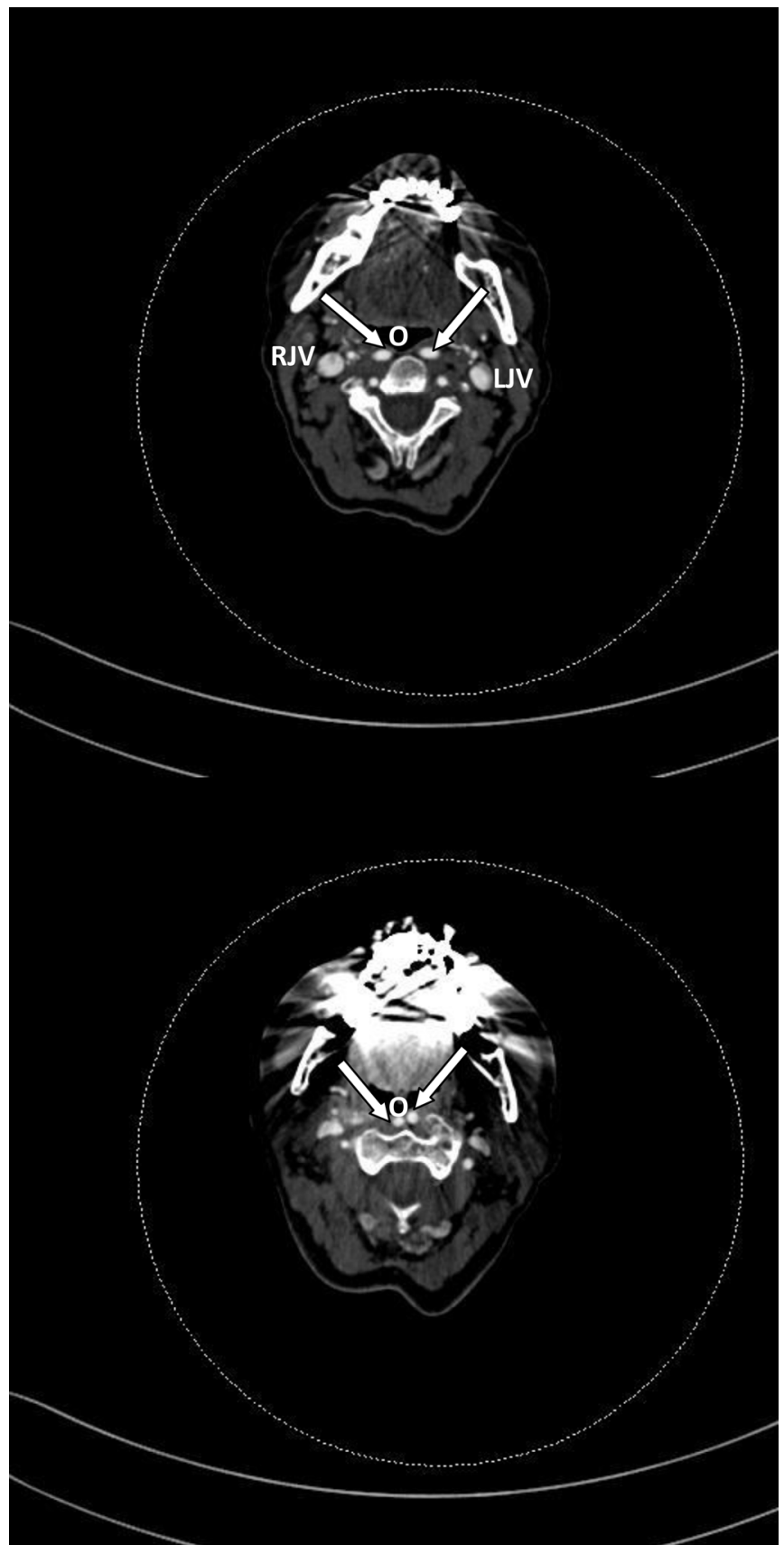

Fig. 3. Axial contrast-enhanced CT-scan. The axial section at the level of the oropharynx presents medially curved ICA which is coming together in the retropharyngeal space (white arrows). This kind of picture can be also called "kissing carotids" to visualise closeness and further drifting apart the both aberrant internal carotid arteries. Additionally, presented imaging shows the close relation of the vessels to the oropharyngeal mucosa which 
in the clinical examination arises as the pulsating masses. Notice that the position of the internal jugular vein remains unchanged. Recognising tubular nature of tortuous arteries by radiologists is a key point in differential diagnosis (distinguishing from the mass lesions). $\boldsymbol{O}$ - oropharynx, $\boldsymbol{R} \boldsymbol{J V}$ - the right internal jugular vein, $\mathbf{L J V}$ - the left internal jugular vein.

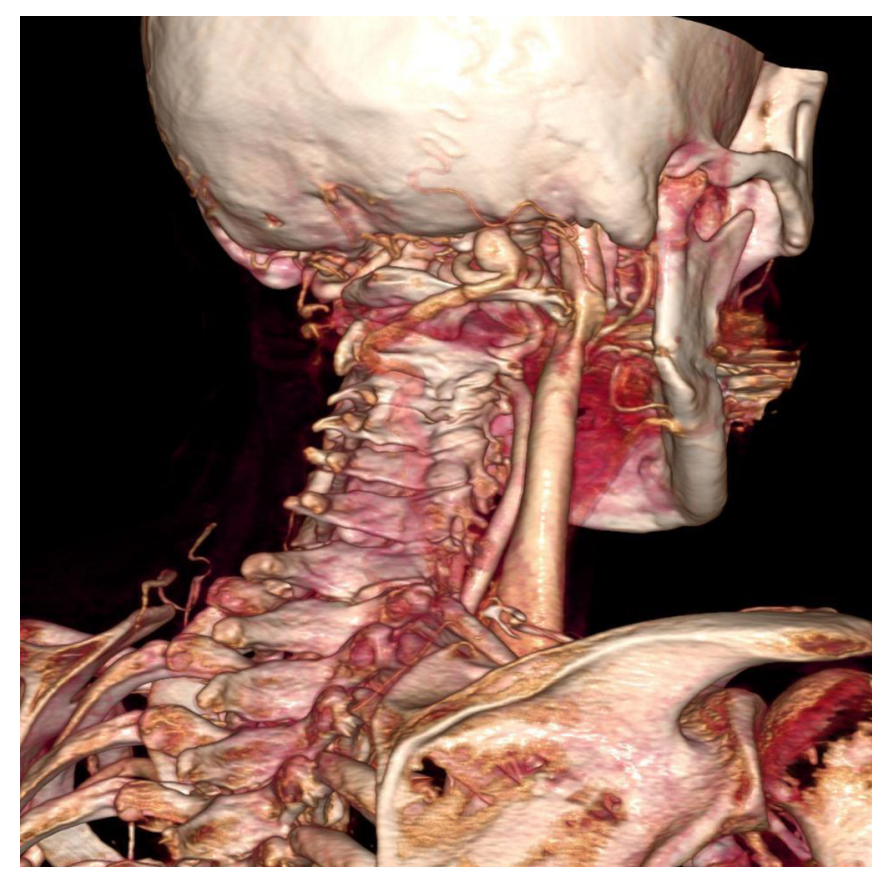

Fig. 4. Coronal volume rendered image from CTA (Computed Tomography Angiography) - reconstruction. A $\mathrm{S}$-shaped segment of the right ICA at the level of C2 is well visible. This kind of imaging best illustrates an exact appearance of the carotid arteries in the retropharyngeal space.

\section{DISCUSSION}

\section{Anatomy}

The internal carotid artery (ICA) originates from the carotid bifurcation at the level of C3-C4 (C2-C3 in children) as a branch of the common carotid artery, passes through the carotid triangle in the carotid sheath collectively with the internal jugular vein (laterally) and vagus nerve (located between these vessels) and ascends toward the base of the skull. After reaching the carotid canal within the petrous part of the temporal bone begins its intracranial course. The terminal branches contribute to the circle of Willis and provide blood supply to the major part of the hemispheres and orbits; some ramifications also collaborate with the external carotid system to create a vascular plexus in the frontonasal area $[5,11,12]$. The carotid sheath, which is actually a pillar of fascia surrounding the neurovascular triad, creates the lateral border of the retropharyngeal space, the fascial space within the neck spreading between the buccopharyngeal fascia anteriorly and prevertebral fascia posteriorly, typically filled with the lymph nodes and considered a potential way for disseminating infections. Other important anatomical structures close to the ICA include the glossopharyngeal nerve, hy- poglossal nerve, cervical plexus and external carotid artery $[1,5,10,11,12]$.

As a rule, the extracranial course of the ICA is straight without giving off any branches [13]. However, a slightly curved, S-shaped carotid artery is a kind of anatomical variant, especially in elderly [11]. Besides, some gentle abnormalities in the geometry and paths are frequently noticed during ultrasonographic and angiographic examination in the clinical practice $[3,14]$. Nonetheless, a kinking, tortuous or forming a loop course of the ICA is not a common finding in the general population and can disarray the physical examination and diagnostic procedures in either symptomatic or relatively healthy patients.

\section{Classification of carotid tortuosity}

A lot of definitions of "tortuosity" have been used in the literature which causes confusion in the nomenclature $[3,9]$. Some authors have separated the terms "tortuosity/coiling", described as any alteration in the shape and route of the artery, from "kinking", and considered to be associated with stenosis and atherosclerotic changes within the vessel $[8,15]$. Paulsen (2000) in his studies on cadavers differentiates between straight course, curved course (forming C- or S-shape), kinking (acute angulation of the vessel) and coiling (creating a loop or double loop). This classification relies on assessment of the artery's shape and can be useful for clinicians, but subsequent divisions proposed by other authors that include the severity of arterial angulation and presence of atherosclerosis, seem to be more valuable regarding the clinical implications [9]. The classification which assumes evaluating the degree of kinked segments' angle primary proposed by Metz (1961) and modified later by many of researchers may be helpful in assessing the risk of cerebrovascular insufficiency and the occurrence of symptoms [2, 3, 8, 9, 15, 16, 17]. According to that, the hemodynamically significant kinking occurs when an angle is lower than $60^{\circ}$ [17]. In our case, we prefer the terms "tortuous" or "aberrant" ICAs to emphasise their deviated but not forming a loop course and lack of the stenotic lesions.

The first reported cases of the atypical ICAs and their clinical implications come from the 19th century, particularly in relation to possible difficulties in providing common surgical procedures e.g. tonsillectomy. Cairney (1924) described ten aberrant vessels found in the subjects dissected in his department and, as well as Jackson (1933), invoked the topographical relations with the tonsillar fossa $[18,19]$. He also emphasised the clinical signs as "the observation of pulsating vessels in the pharynx in the living subject" [18] which he noticed in children and paid attention to the congenital anomalies as a causative factor.

\section{Epidemiology}

An assessment of the prevalence of carotid aberrancies based on first studies has been underestimated and biased due to the fact that most of them had been carried out on cadavers $[18,19]$. Thus, the results were limited by the predominance of elderly subjects in the study group. Nevertheless, this type of investigation, performed many times 
afterwards as well, let to distinguish basic patterns of an abnormal way of the ICAs from the carotid bulb to the petrosal bone [9, 20]. The development of contemporary imaging techniques and their accessibility allowed to evaluate the prevalence by examining living subjects, using classical angiography, computed tomography, magnetic resonance and Doppler ultrasound.

Most of the authors have estimated the frequency of ICA's aberrancy to be in a wide range between 10-43\% [2, 3. 7]. The predominance of tortuous ICAs in females and relation to ageing and hypertension are regularly reported $[2,3,15]$. Although the unilateral tortuosity of the right ICA has been more often described, an abnormal course of the left ICA and bilateral changes are not much rarer. Taking into account the anatomy, the right carotid artery seems to be more prone to deviation, because of its origin and shorter length $[8,21,22]$. However, there are a lot of discrepancies which arise from differences in the methods, analysed population, terminology, etc. $[2,3,7,8,9,15,17$, 23].

The causes of an aberrant course of the ICA are unclear. Nevertheless, there is a general conviction that either congenital anomalies or acquired factors may bring about it $[2,15,24]$.

\section{Embryology}

The embryological development of the large neck vessels has a particular multistage course. During the fourth and fifth weeks of development, each of the pharyngeal arches receives its own pair of the vessels called the aortic arches. These arteries arise anteriorly from the aortic sac and are interconnected posteriorly with the dorsal aorta (Fig. 5a, b). Up to the 6th week, the 1st, 2nd and 5th aortic arches in the majority disappear, whereas the others contribute to form the arch of aorta, carotid system and pulmonary arteries. The third pair of aortic arches gives the beginning to both common carotid arteries, external carotid arteries and the lower part of the internal carotid arteries. The upper segments of the internal carotids come from the dorsal aorta. The fourth left aortic arch is predominant and forms a major part of the arch of the aorta and proximal segment of the left subclavian artery. The right one, by contrast, forms the part of the right subclavian artery. Both the right and left sixth aortic arches grow and transform into the pulmonary arteries, the left one contributes to forming the ductus arteriosus as well. At about 40 days the heart descends from its primary cervical position into the chest which causes straightening of initially curved vessels and leads to the final appearance of the aortic arch system [11, $25,26]$. Any disturbances in this process could give rise to congenital vascular anomalies [27].
A.
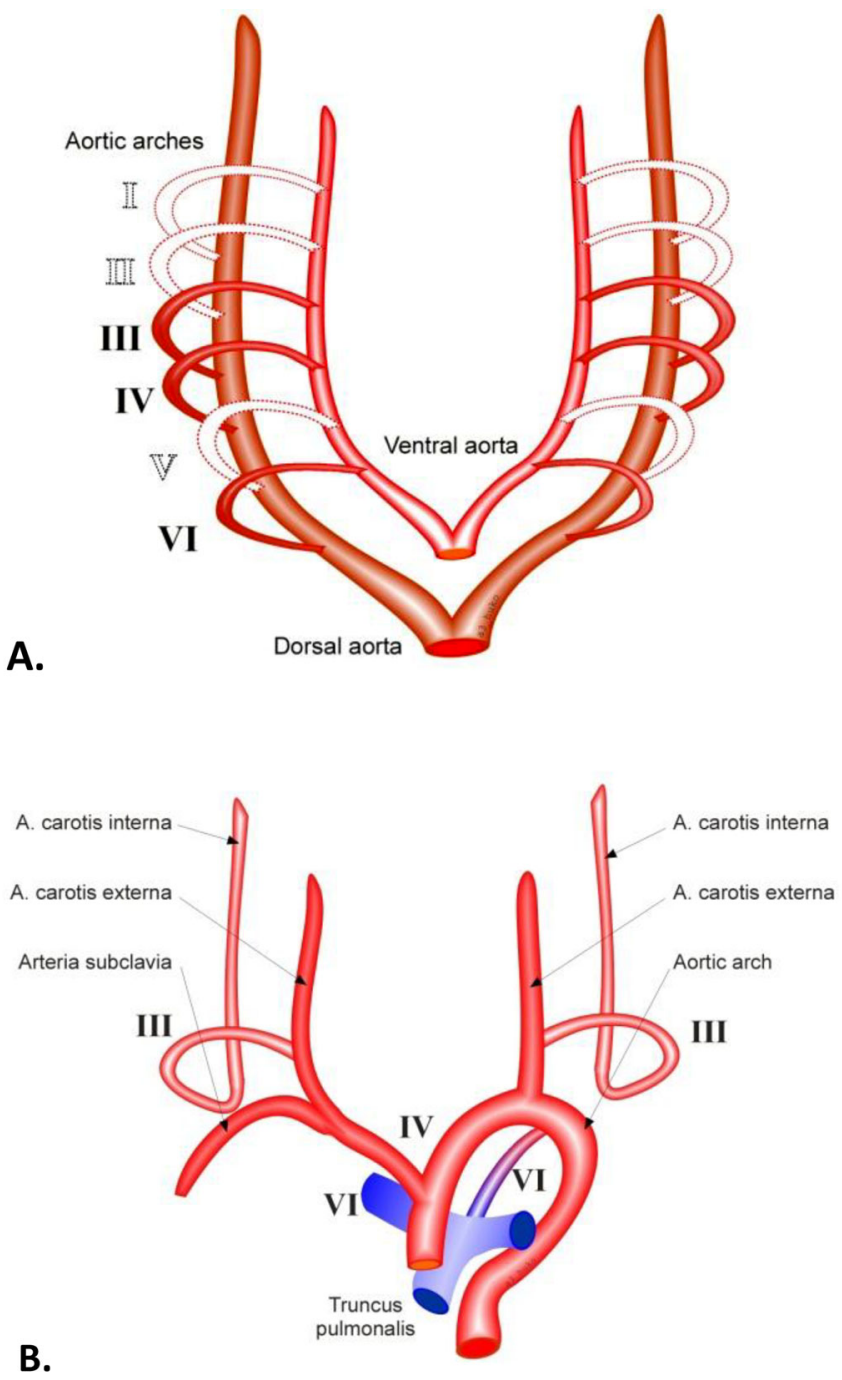

Fig. 5a, b. Development of the aortic system from the aortic arches and dorsal aorta (full description in text). A. Six aortic arches in the 5th week embryo. Regressing arches are depicted in white. B. Aortic arches and dorsal aorta after transformation into final foetal aortic system. Note coiled ICAs which straighten up with heart descending into the chest.

\section{Congenital tortuous ICA}

The abnormalities of the carotid arteries may affect either their development or their course and position within the neck $[5,10,28]$. Many arterial variations have been described in the literature: underdeveloped vessels (agenesis, aplasia and hypoplasia, the rare morphological malformations [5]), varieties of the origin or bifurcation of the common carotid artery (one bicarotid trunk called "Bovine arch", various levels of branching off $[4,29,30])$, dextral aortic arch, preserved foetal vessels (the trigeminal and hypoglossal arteries are the most frequent persistent extracranial branches of the internal carotid arteries [25]) and, at last, diverse patterns of an aberrant course of the arteries including the extra- and intracranial segments (occasion- 
ally observed within the temporal bone $[31,32])$ of the internal carotid, external carotid and also common carotid arteries. There are many reports of abnormalities within the carotid system considered to be congenital, in both the children and adults. Curiously, these disturbances can affect not only one artery but two or more simultaneously [29, 33, 34]. Moreover, inappropriate developed vessels with coexisting aberrancy of another artery were also observed [35].

As a rule, the severe anomalies are noticed immediately or early after birth, because of the visible and evident clinical symptoms. However, as it can be seen in the majority of cases, mild and even moderate variants remain typically asymptomatic and are recognised incidentally, during other diagnostics. The diagnosis may also be made when the symptoms of cerebrovascular disease occur in adulthood [5]. Nowadays more and more cases are identified due to the broader accessibility of the diagnostic imaging techniques, as in our patient.

\section{Acquired tortuous ICA}

The only acknowledged causative factors for altering the walls and the form of ICAs are ageing and hypertension $[15,24]$. Even though the prevalence in women is clear and well-documented, no explanation for this tendency exists. In reviews, there is an assumption that the alterations within the vessel's wall may be connected with hormonal disorders [15].

\section{Hypertension}

The correlation between carotid aberrancy and hypertension has been confirmed [24]. Numerous retrospective studies as well as case reports denote the concomitance of these pathologies [2]. Disturbances in the blood flow within the vessels when the blood pressure is elevated can press the vascular wall leading to an alternation of the vessel's course, particularly in elderly. Currently, there is a general conception that exposed to an increased blood pressure arteries are prone to deformations $[3,17]$. There is also an association between duration of hypertensive disease and rising tendency to the arterial deviation. Even though the diabetes mellitus and cigarette smoking are considered the reasons of twisting the vessels within the human body, their relationship with carotid tortuosity has not been proved in the studies [2, 24].

\section{Changes within the arterial wall}

It is acknowledged that the architecture and quality of the arterial walls change with ageing. Due to the alteration caused by degradation, fragmentation and chemical structure rearrangements of elastin, decreasing the number of smooth muscle cells and the collagen's content changes within the walls of elastic arteries (major human arteries), the compliance and endurance of the vascular wall decline [36]. While this remodelling is influential in the aneurysm formation, it might be also one of the predisposing factors to arterial curving and translocation. Regarding the ICAs, it is good to remember that the structures within the carotid sheath above the hyoid bone are not fully separated from the surrounding tissues because the fascia building the sheath is incomplete at this level. That poses a potential risk of shifting the arteries medially into the retropharyngeal space [8]. Furthermore, passing through the neck, the ICA with decreasing its diameter gradually changes its character from an elastic (conducting) artery to muscular (distributive) artery which means different conformation of the vascular wall. Owing to this fact, in the literature the term "metaplasia" has been used as a hypothesis of possible transformative process within the arterial wall in this region, similarly to other "transition zones" within the human body [37].

\section{Genetic disorders}

It is widely recognised that some genetic disorders such as Marfan syndrome, fibromuscular dysplasia and recently defined diseases like Loeys-Dietz syndrome (tortuous aneurysmal vessels due to mutations in the TGF- $\beta$ receptor) and Artery Tortuosity Syndrome (ATS, an autosomal recessive disorder connected with mutation in the SLC2A10 gene), may also cause the ICA's aberrancy by impacting the architecture and composition of an arterial wall $[36,38]$. Since these conditions affect the connective tissue, vascular changes can occur during whole life, as well as disturbances within other structures throughout the body, such as skin, joints or gastrointestinal tract. However, the patients need distinctive medical approach focused on the all clinical symptoms.

\section{Atherosclerosis}

An association with atherosclerosis remains unclear [2]. Some researchers, on the basis of general pathophysiological knowledge, suggest that the presentation of atherosclerotic plaques in the arteries can have an influence on rearranging the vessel's shape as a consequence of the disturbances in velocity, inappropriate pressure distribution and turbulent blood flow within the vessels. These hypotheses may arise from the fact that several reports describe "kinking" as an alteration always connected with the presence of stenotic and/or atheromatous lesions. Nevertheless, other randomised studies show that there is no relation between the prevalence and concomitance of the abnormal course of the carotid arteries and atherosclerosis [2]. Indeed, this issue is difficult to investigate, because the atherosclerotic disease of the carotid arteries is a common condition in the general population. Thus the coexistence with kinking vessels can be random.

Since no elevated systolic blood pressure or other concomitant acquired vascular disorders were observed in our patient, and the deflections of the ICAs were quite symmetrical we would suppose, that this is the case of congenital tortuous ICAs.

\section{Co-relation with stroke}

With reference to atherosclerosis, a question arises as to if the internal carotid tortuosity can represent a risk factor for stroke and cerebral insufficiency. It may look obvious that bending or curving of the vessel leads to narrowing and even occlusion of the vascular lumen. Indeed, 
the aberrant ICAs are responsible for symptoms of cerebral perfusion disturbances in $4-16 \%$ of cases [37]. The studies performed in vivo as well as in vitro stimulations demonstrate that arterial kinking induces pressure drop (there is a pressure difference between the beginning and the end of kinked segment and this difference increases with the decreased angle of curving [39]) and the regional blood flow in the brain declines when elongated extracranial carotid segments have occurred [17]. On the other hand, if the internal carotid arteries have an atypical course, any rapid movements of the head and neck or their immobilization in a non-neutral position may trigger the temporary ischemic symptoms like dizziness, blackouts, syncopes, visual disturbances, and further, when prolonged, cause a Transient Ischemic Attack (TIA) and even a full ischemic stroke [2, 17, 37, 40]. Nonetheless, there is a discrepancy in the literature. Some authors have signalised a higher risk of cerebrovascular insufficiency in relation to carotid aberrancy, however other researchers have distinctly contradicted this connection [2]. Since the prevalence of stroke incidents due to an atypical course of ICAs is similar to the frequency in the general population (approximately 6$15 \%$ increasing with age), the concomitance of the atherosclerotic disease and high blood pressure, regarded to be the major risk factors for cerebral ischemia, seems to be essential [37, 41, 42].

\section{Clinical symptoms}

As already mentioned, the aberrant course of the ICAs is usually an occasional finding during diagnostic procedures for other reasons, because typically, in more than $80 \%$ of patients, it remains clinically silent $[8,43]$. But in some cases, certain signs can appear. The symptoms connected with cerebrovascular ischemia were mentioned above. Besides them, any others may arise from an atypical localisation of these vessels caused by their changed shape or transposition. The patients' complaints include a sore throat, dysphagia, foreign body sensation (known as the globus syndrome), dysphonia (when the recurrent laryngeal nerve is irritated), problems with swallowing $[1,10$, 28]. Obstructive sleep apnoea has also been noted [44, 45]. In the physical examination of the oral cavity and oropharynx, a protruding and pulsating retropharyngeal mass can be noticed as a result of an intimate contact of the tortuous arteries with the pharyngeal mucosa [10, 18, 28, 46, 47]. When the carotid arteries are deviated laterally, the pulsation within the neck region might be observed [46]. In our case, the patient reported past episodes of acute short-lasting dyspnoea and dysphonia. The endoscopic evaluation did not show any changes in the laryngeal mobility, however, at the time of examination the patient had no dyspnoea, and the mild dysphonia was judged to be attributable to the infection of the upper airways. We may only speculate that, in certain conditions, the tortuous ICAs caused transient dysfunction of the vagus nerve and its branches involved in the laryngeal motility, which can result in dyspnoea.

\section{The level of arterial deviation}

The level of the ICAs' medialization in the affected patients should be defined in view of the vicinity of clinically important anatomical structures and regions. The arterial tortuosity in the hypopharynx may trigger the symptoms of the recurrent laryngeal nerve's irritation and cause the voice disturbances. It also poses a potential risk of severe haemorrhage during neck surgeries, such as removal of laryngeal cancer [48]. The aberrancy at the level of oropharynx can be seen in the physical examination as the retropharyngeal pulsating masses resembling other abnormalities like vascular tumors, abscesses or aneurysms [10, 18, 21, 28, 48, 49] and might bring about several problems with breathing and swallowing (dysphagia, dyspnoea, obstructive sleep apnoea $[10,44,45,46]$. An epipharyngeal deviation may hinder the procedures within the nasopharynx and lead to the obstruction of nasal airways. At last, an atypical course of the ICAs within the temporal bone can result in nonspecific signs (including hearing loss and tinnitus) or carry a threat of bleeding during the middle ear interventions [31, 32]. Many authors have described the hypopharyngeal and oropharyngeal medialization $[1,4,7$, $8,10,21,28,33,44,45,46]$. Nonetheless, the reports concerning the epipharyngeal and intratemporal aberrations are noticeably rarer [19, 22, 31, 32].

\section{Relation to the pharyngeal mucosa}

Not only the level of ICAs tortuosity is compelling, but also their relation to the posterior pharyngeal wall [1, $6,23,47]$. Direct proximity to the tunica mucosa may be visible in the physical examination as a pulsing widening of the retropharyngeal soft tissue [6], that poses a risk of laceration of the arteries during diagnostic or surgical procedures within the upper airways. On the other hand, tortuous vessels hidden in the deeper area might be a surprising finding for radiologists which, in turn, can hinder endovascular interventions $[13,31,50]$. In our case, the abnormal way of ICAs involves the level of oropharynx and epipharynx just below the mucosa, that could be noticed as a protruding, pulsating retropharyngeal masses. Moreover, bilateral and quite parallel arterial course presented by this patient is less frequent than unilateral changes and no commonly reported in the literature $[15,46]$.

Considering the carotid tortuosity as a possible differential diagnosis is essential for two reasons. First, similar symptoms can represent the potentially dangerous conditions such as aneurysm [21], pseudoaneurysm [49], abscess, neoplasm (including vascular tumours [10, 48]), metastatic or atypically located lymph node [51], which require an adequate medical approach. In contrast, a misdiagnosis and undertaking an inappropriate surgical management poses a threat of profuse bleeding, that could be avoided. 
Possible complications during head and neck surgeries

Although the carotid aberrancy often remains asymptomatic and is considered by several researchers to be a curiosity [2], recognising and setting it down in the patient's chart is important. As was already remarked by investigators in the last century, the tortuous and atypical extracranial course of the ICAs carries a risk of severe haemorrhage when surgeries are performed, even if they are the common and frequent procedures like tonsillectomy or adenoidectomy [1, 10, 19, 23, 44]. To emphasise this problem, several authors have used the term "dangerous loop" with reference to an aberrant cervical part of the ICA that stays at risk during surgeries, maintains direct submucosal course and may cause an appearance of pulsative bulge on the retropharyngeal wall $[6,7,8,9]$. While the reported profuse bleeding as a result of iatrogenic injury of the tortuous ICAs is a rare complication of head and neck operations in the general population [43], this problem should not be underestimated by physicians.

In the otolaryngologic point of view, many invasive procedures may give rise to damage of the aberrant carotids. Early (in 24 hours) or late (after 7 days) haemorrhage following routine oropharyngeal surgeries like tonsillectomy or adenoidectomy is a well-known intracacy. The pseudoaneurysm formation succeeding tonsillectomy has been also noted [13]. However, the cases of post-operative, sometimes life-threatening bleeding due to tortuosity of the extracranial neck arteries, though uncommon, are reported in the literature as well, more often in relation to tonsillectomy $[1,21,23,47,52]$. When an atypical course of ICAs is recognised prior the planned tonsillectomy, the operation might be postponed [43]. Most of these surgical interventions are performed by young, less experienced doctors which increases a risk of potential intra-operative injury [47]. Owing to the fact that the diagnostic imaging is not typically provided before tonsils and adenoids removal, the accurate and conscientious initiatory oropharyngeal examination, including assessment of the peritonsillar region, is essential [21, 43, 47].

Many other pharyngeal manipulations carry a risk of blood loss when ICAs tortuosity occurs. Uvulopalatopharyngoplasty and drainage of peritonsillar and parapharyngeal abscess are the examples of another frequent surgical interventions [22, 23, 46, 47]. Routine outpatient procedures such as aspiration biopsy or endoscopic examination of the upper airways may, likewise, harm the atypical ICAs when they pass through the neck in the close vicinity to the pharyngeal wall $[1,6,21,23,46]$. Lastly, open surgeries within the head and neck region, like laryngeal cancer or metastatic lymph nodes resection, can be disturbed by abnormal anatomical appearance of the carotid system and lead to severe intra-operative haemorrhage [ 48 , 53].

Anaesthesiologists have to take it into account as well, because either intubation or transoral local anaesthetic glossopharyngeal nerve block may cause damage and laceration of the oropharyngeal mucosa and submucosal soft tissues $[44,53]$. Injuries of the posterior pharyngeal wall are also mentioned in the reviews as a result of inserting nasogastric tubes and endoscopic ultrasound (EUS) probes [44].

The abnormal carotid arteries can hinder the endoluminar treatment of atherosclerotic arterial disease or aneurismal lesions too $[13,31,50]$. In these cases, open surgical repair might be required. However, studies have proved that intravascular access through tortuous arterial vessels is unrelated to an increased number of failures or post-operative complications $[40,50]$. Since the vertebral artery injury is considered one of the most serious complications following anterior cervical spine surgeries, neurosurgeons should keep in mind that the medially deviated ICAs may impede this way of treatment too [54].

\section{Diagnostic imaging}

Any protuberant mass recognised within the pharynx during physical examination or endoscopy should be evaluated with more precise diagnostic measures. The best imaging technique to visualise an aberrant carotid artery is the Computed Tomography Angiography (CTA) [7, 10]. It lets to depict an exact course of the vessels in relation to surrounding tissues as well as detect the possible presence of intravascular calcifications. Currently, it is widely available and may be used in the most of the cases $[2,7]$. Even though conventional arteriography allows to receive an appropriate vascular projection, it has not been recommended anymore, because of its invasiveness [10]. Magnetic Resonance Imaging (MRI) provides a right assessment of the soft tissues and has been strongly advised by some authors to assess carotid aberrancy [47]. However, comparing to CTA, this method is less accessible, more pricey and requires longer immobilisation of the patient to avoid artefacts arisen from head and neck movements such as swallowing $[7,10]$. CTA and MRI of the brain also give information about the ischemic lesions [17]. Doppler ultrasound can be used in screening tests as an economic, common and non-penetrative tool which enables to evaluate the hemodynamic state of the carotid arteries [2], but the results may not be satisfying because of non-obvious visualisation of the vessel's course [7].

\section{Treatment}

Owing to the fact, that no symptoms of internal carotid tortuosity at the level of the pharynx are observed in the majority of cases, treatment of this condition is not essential. The patient ought to be aware of possible mishaps which could occur during manipulations within the neck region, and this diagnosis has to be reported in the patient's medical history. Nevertheless, when any clinical signs appear impacting normal daily activity or posing a risk of cerebral ischemia, surgical correction should be considered $[2,17,22,40]$. According to the research, operative treatment may be effective, provides a relief of symptoms and it is not connected with increased risk of complications. However, there are no numerous and credible publications concerning the clearly defined surgical approach in these cases. The long-term follow-up has been still insufficient $[17,40,50]$. 


\section{CONCLUSIONS}

An atypical retropharyngeal course of the ICAs causing pulsation of the posterior pharyngeal wall is an uncommon finding during a physical examination. However, regarding the numerous publications, the carotid aberrancies are not so rare in the general population as we had thought. Most of the patients sustain asymptomatic and do not require any treatment. Nonetheless, when the symptoms occur, the surgical approach should be considered. Medical specialists such as otolaryngologists, radiologists, anaesthesiologists and surgeons should be aware of the possible clinical implications of carotid tortuosity to provide an appropriate medical approach. The physicians, as well as the patients, have to bear in mind that even minimally invasive manipulations within the neck region can result in potentially life-threatening bleeding.

\section{REFERENCES:}

1. Gupta A, Shah AD, Zhang Z, Phillips CD, Young RJ. Variability in the position of the retropharyngeal internal carotid artery. Laryngoscope. 2013 Feb;123(2):401-3. [PubMed] [CrossRef]

2. Togay-Isikay C, Kim J, Betterman K, Andrews C, Meads D, Tesh P, et al. Carotid artery tortuosity, kinking, coiling: stroke risk factor, marker, or curiosity? Acta Neurol Belg. 2005 Jun;105(2):68-72. [PubMed]

3. Zenteno M, Vinuela F, MoscoteSalazar LR, Alvis-Miranda H, Zavaleta R, Flores A, et al. Clinical implications of internal carotid artery tortuosity, kinking and coiling: a systematic review. Romanian J Neurosurgery. 2014; 21(1):50-59.

4. Bissacco D, Domanin M, Schinco G, Gabrielli L. Bovine Aortic Arch and Bilateral Retroesophageal Course of Common Carotid Arteries in a Symptomatic Patient. Vasc Specialist Int. 2016 Sep;32(3):133-136. [PubMed] [CrossRef]

5. Clarós P, Bandos R, Gilea I, Clarós A Jr, Capdevila A, García Rodríguez J, et al. Major congenital anomalies of the internal carotid artery: agenesis, aplasia and hypoplasia. Int J Pediatr Otorhinolaryngol. 1999 Jun 15;49(1):69-76. [PubMed] [CrossRef]

6. Fix TJ, Daffner RH, Deeb ZL. Carotid transposition: another cause of wide retropharyngeal soft tissues. AJR Am J Roentgenol. 1996 Nov; 167(5): 1305-7. [PubMed] [CrossRef]

7. Gossner J, Manka R, Larsen J. Aberrations of the Cervical Carotid Artery Which May Be Dangerous in Pharyngeal Surgery-A Computed Tomographic Study. Advances in Computed Tomography. 2013; 2:29-33.

\section{[CrossRef $]$}

8. Munoz A, De Vergas J, Crespo J. Imaging and clinical findings in patients with aberrant course of the cervical internal carotid arteries. Open Neuroimag J. 2010 Nov 5;4:174-81. [PubMed] [CrossRef]

9. Paulsen F, Tillmann B, Christofides C, Richter W, Koebke J. Curving and looping of the internal carotid artery in relation to the pharynx: frequency, embryology and clinical implications. J Anat. 2000 Oct;197 Pt 3:373-81. [PubMed] [CrossRef]

10. Prokopakis EP, Bourolias CA, Bizaki AJ, Karampekios SK, Velegrakis GA, Bizakis JG. Ectopic internal carotid artery presenting as an oropharyngeal mass. Head Face Med. 2008 Aug 26;4:20. [PubMed] [CrossRef]

11. Bochenek A, Reicher M. Anatomia czlowieka. Podrecznik dla studentów i lekarzy. Tom 5. Red. Warszawa: Wydawnictwo Lekarskie PZWL, 1960. Wydanie IV (I): 230-235, 248-250, 255-268.

12. Drake R, A. Vogl W, Mitchell AWM. Gray's Anatomy for Students: With Student Consult Online Access, 3e. 3 edition. Philadelphia, PA: Churchill Livingstone. 2014: 10001011.

13. Xenos ES, Orr N, Valentino J. Internal Carotid Pseudoaneurysm Associated with Tortuosity after Tonsillectomy: A Case Report. Int J Angiol. 2012 Sep;21(3):159-62. [PubMed] [CrossRef]

14. Wong YS, Ong CT, Sung SF, Wu $\mathrm{CS}, \mathrm{Hsu}$ YC, Su YH, et al. Association Between Abnormal Course of Carotid Artery and Cerebrovascular Disease. Acta Neurol Taiwan. 2014 Sep;23(3): 90-94. [PubMed]
15. Sacco S, Totaro R, Baldassarre M, Carolei A. Morphological variations of the internal carotid artery: Prevalence, characteristics and association with cerebrovascular disease. Int J Angiol. 2007 Summer;16(2):59-61. [PubMed]

16. Ovchinnikov NA, Rao RT, Rao SR. Unilateral congenital elongation of the cervical part of the internal carotid artery with kinking and looping: two case reports and review of the literature. Head Face Med. 2007 Jul 25;3:29. [PubMed] [CrossRef]

17. Radak D, Babiæ S, Tanaskoviæ S, Matiæ P, Sotiroviæ V, Stevanoviæ P, et al. Are the Carotid Kinking and Coiling Underestimated Entities? Vojnosanit Pregl. 2012 Jul; 69(7): 616-19. [CrossRef]

18. Cairney J. Tortuosity of the cervical segment of the internal carotid artery. J Anat. 1924 Oct;59:87-96. [PubMed]

19. Jackson JL. TORTUOSITY OF THE INTERNAL CAROTID ARTERY AND ITS RELATION TO TONSILLECTOMY. Can Med Assoc J. 1933 Nov;29(5):475-79. [PubMed]

20. Iwanaga J, Watanabe $\mathrm{K}$, Tsuyoshi S, Tabira Y, Yamaki K. Tortuous Common Carotid Artery: A Report of Four Cases Observed in Cadaveric Dissections. Case Rep Otolaryngol. 2016 (2016), Article ID 2028402 , 4 pages. [CrossRef]

21. Bektas D, Caylan R, Korkmaz $\mathrm{O}$, Savas FS. Acquired and congenital internal carotid artery anomalies in two cases: an important threat for the otolaryngologist. Kulak Burun Bogaz Ihtis Derg. 2004; 13(1-2):35-37

22. Singhal M, Prabhakar N, Rohit MK, Khandelwal N. Retropharyngeal Course of Right Internal Carotid Ar- 
tery. J Postgrad Med.Edu Res. 2014; 48(4):201-202. [CrossRef]

23. Ozgur Z, Celik S, Govsa F, Aktug H, Ozgur T. A Study of the Course of the Internal Carotid Artery in the Parapharyngeal Space and Its Clinical Importance. Eur Arch Otorhinolaryngol. 2007 Dec 1; 264(12): 1483-89. [PubMed] [CrossRef]

24. Oliviero U, Cocozza M, Picano T, Policino S, Russo N, Fazio S, Coto V, Saccá L. Prevalence of Carotid Kinking and Coiling in a Population at Risk. Vasc Endovasc Surg. 1997 Jan 1;31(1):43-49. [CrossRef]

25. Dungan DH, Heisermann JE. The carotid artery. Embryology, normal anatomy, and physiology. Neuroimag Clin N Am. 1996 Nov;4: 789-99.

26. Sadler TW. Langman's Medical Embryology. 13 edition. Philadelphia: LWW, 2014: 202-207

27. Matussek VK, Sapundzhiev N, Werner JA, Kaschke O. OrtnerSyndrom - gefährlicheRaritat. HNO-Nachrichten. 2005; 6:36-38.

28. Bhandarkar AM, Nayak R, Chidambaranathan N, Gopinath D. Beware of a Pulsating Oropharynx. BMJ Case Rep. 2014; Nov 25, 2014 [PubMed] [CrossRef]

29. Deshpande SH, Nuchhi AB, Bannur BM, Patil BG. Bilateral Multiple Variations in Carotid Arteries-A Case Report. J Clin Diagn Res. 2015 Dec;9(12):AD01-AD03. [CrossRef]

30. Uchino A, Saito N, Okada Y, Kozawa E, Nishi N, Mizukoshi W, et al. Variation of the Origin of the Left Common Carotid Artery Diagnosed by CT Angiography. Surg Radiol Anat. 2013 May;35(4):339-42. [PubMed] [CrossRef]

31. Jain R, Marotta TR, Redekop G, Anderson DW. Management of aberrant internal carotid artery injury: A real emergency. Otolaryngol Head Neck Surg. 2002 Nov;127(5):470-473

32. Muderris T, Bercin S, Sevil E, Cetin H, Kiris M. A Potentially Catastrophic Anatomical Variation: Aberrant Internal Carotid Artery in the Middle Ear Cavity. Case Rep Otolaryngol. 2013; 2013:743021. [PubMed] [CrossRef]
33. Cvetko E. Concurrence of bilateral kinking of the extracranial part of the internal carotid artery with coiling and tortuosity of the external carotid artery - a case report. Rom J Morphol Embryol. 2014;55(2):433435.

34. Vinnakota S, Nandagiri B, Neelee J. A rare association of curving and looping of internal carotid artery and variation in the branching pattern of the external carotid artery - a case report. Int J Biol Med Res. 2011; 2(3): 822-823.

35. Virvilis D, Koullias G, Labropoulos N. Bilateral retroesophageal course of the carotid arteries. J Vasc Surg. 2013 May 1;57(5):139597. [PubMed]

36. Tsamis A, Krawiec JT, Vorp DA. Elastin and collagen fibre microstructure of the human aorta in ageing and disease: a review. J R Soc Interface. 2013 Mar 27;10(83):20121004 [PubMed] [CrossRef]

37. La Barbera G, La Marca G, Martino A, Lo Verde R, Valentino F, Lipari D, Peri G, Cappello F, Valentino B. Kinking, coiling, and tortuosity of extracranial internal carotid artery: is it the effect of a metaplasia? Surg Radiol Anat. 2006 Dec;28(6):573-580.

38. Han HC. Twisted blood vessels: symptoms, etiology and biomechanical mechanisms. J Vasc Res. 2012; 49(3):185-197.

39. Wang L, Zhao F, Wang D, Hu S, Liu J, Zhou Z, et al. Pressure Drop in Tortuosity/Kinking of the Internal Carotid Artery: Simulation and Clinical Investigation. Biomed Res Int. 2016; 2016:2428970 [PubMed]

40. Hao JH, Zhang LY, Lin K, Liu WD, Zhang SG, Wang JY, Li G, Wang LX. Surgical Revascularization of Symptomatic Kinking of the Internal Carotid Artery. Vasc Endovasc Sur. 2016 Oct;50(7):470-474.

41. Mozaffarian D, Benjamin EJ, Go AS, Arnett DK, Blaha MJ, Cushman M, Ferranti S, et al. Heart Disease and Stroke Statistics-2015 Update: A Report from the American Heart Association. Circulation 2015 Jan 27;131(4): e114,e119.

42. Tse GG, Masuda EM, Mc
Murtray AM, Nakamoto BK. Coiled internal carotid arteries associated with bilateral sequential strokes. Case Rep Vasc Med. 2013; 2013:929530. [PubMed] [CrossRef]

43. Shihada R, Goldsher M, Braun J, Luntz M. Aberrant Carotid Artery as an Incidental Finding before Tonsillectomy. Ear Nose Throat J. 2010 May;89(5):E17-18. [PubMed]

44. Marcucci C, Thomas P, Sewell DA. Retropharyngeal Carotid Artery: An Important Anatomic Variation for the Anesthesiologist. Anesthesiology. 2009 Aug 1;111(2):454-455. [CrossRef]

45. Picel AC, Davidson TM. An Aberrant Internal Carotid Artery Discovered during Evaluation of Obstructive Sleep Apnea: A Report of 2 Cases with Consideration of a Possible Association. Ear Nose Throat J. 2011 Jan; 90(1):29-31. [PubMed]

46. Beriat GK, Ezerarslan H, Kocatürk S, Mýhmanoðlu AF, Kuralay E. Pulsatile oropharyngeal and neck mass caused by bilateral tortuous internal carotid artery: a case report. Kulak Burun Bogaz Ihtis Derg. 2010 Sep-Oct;20(5):260-3 [PubMed]

47. Galletti B, Bucolo S, Abbate G, Calabrese G, Romano G, Quattrocchi $\mathrm{C}$, et al. Internal carotid artery transposition as risk factor in pharyngeal surgery. Laryngoscope. 2002 Oct; 112(10):1845-8. [PubMed] [CrossRef]

48. Uzun L, Egilmez OK, Kalcioglu MT, Tekin M. Tortuous Carotid Artery Extended to Neck Level IIb Mimicking the Metastatic Mass. Case Rep Otolaryngol. 2016;2016:1376926. [PubMed] [CrossRef]

49. Tanaka H, Patel U, Shrier DA, Coniglio JU. Pseudoaneurysm of the Petrous Internal Carotid Artery after Skull Base Infection and Prevertebral Abscess Drainage. AJNR Am J Neuroradiol. 1998 Mar;19(3):502-4. [PubMed]

50. Zenteno MA, Santos-Franco JA, Moscote-Salazar LR, Lee A. Endovascular remodeling of tortuous cervical segments of the internal carotid artery that hinder the management of complex intracranial aneurysms. Rom Neuro. 2013 Sep;20(3): 249-259. 


\section{[CrossRef]}

51. Nayak SB. Unusual Looping of the Internal Carotid Artery in Relation to an Enlarged Lymph Node. Int $J$ Anat Var. 2010 Jan 1;3:84-85.

52. Windfuhr JP. An Aberrant Artery as a Cause of Massive Bleeding Following Adenoidectomy. J Laryngol
Otol. 2002 Apr;116(4):299-300. [PubMed]

53. Agrawal R, Agrawal SK. Dangerous anatomic variation of internal carotid artery - a rare case report. Int J Anat Var. 2011; 4:174-76.

54. Wakao N, Takeuchi M Nishimura M, Riew KD, Kamiya
M, Hirasawa A, et al. Risks for Vascular Injury During Anterior Cervical Spine Surgery: Prevalence of a Medial Loop of Vertebral Artery and Internal Carotid Artery. Spine (Phila Pa 1976). 2016 Feb;41(4):293-8. [PubMed]

Please cite this article as: Ziolkowska K, Bachvarov Ch, Sapundzhiev N, Genova P. Bilateral tortuous internal carotid arteries - a case report, otorhinolaryngologic and general clinical implications. J of IMAB. 2017 Jul-Sep;23(3):16571666. DOI: https://doi.org/10.5272/jimab.2017233.1657

Received: 14/05/2017; Published online: 31/08/2017

Address for correspondence:

Klaudia Ziolkowska

Department of ENT, University Hospital Saint Marina Varna,

1, Hristo Smirnenski Blvd, 9010 Varna, Bulgaria

E-mail: klaudia.ziolko92@gmail.com 